\title{
How can directories of open access repositories improve the reuse of learning objects in building engineering?
}

\author{
Victoria-Eugenia Garcia-Vera*, \\ Rosabel Roig-Vila, \\ Pedro Garcia Ferrandez and Pablo Marti
}

\author{
University of Alicante, \\ Carretera San Vicente del Raspeig s/n, \\ 03690, San Vicente del Raspeig, Alicante, Spain \\ Email: vegarcia@ua.es \\ Email: rosabel.roig@ua.es \\ Email: pedro.garcia@ua.es \\ Email: pablo.marti@ua.es \\ *Corresponding author
}

\begin{abstract}
This paper studies the use of directories of open access repositories worldwide (DOARW) to search Spanish repositories containing learning objects in the field of building engineering (BE). Results show that DOARW are powerful tools, but deficiencies (indicated in this study) have to be solved in order to obtain more accurate searches, and to facilitate repository-finding for potential users who are seeking learning objects (LOs) for reuse. Aiming to contribute to the promotion of the reuse of Spanish LOs, this study exposes to the academic community all existing Spanish repositories with LOs, and in particular, the repositories that contain LOs in the field of BE. This paper also studies the critical mass of available content (LOs) in the field of BE in Spain. It has been found to be low.
\end{abstract}

Keywords: repository directories; Spanish repository; open access repository; learning object repository; open education resources; learning objects; learning object reuse; building engineering.

Reference to this paper should be made as follows: Garcia-Vera, V-E., Roig-Vila, R., Garcia Ferrandez, P. and Marti, P. (2015) 'How can directories of open access repositories improve the reuse of learning objects in building engineering?', Int. J. Continuing Engineering Education and Life-Long Learning, Vol. 25, No. 3, pp.274-292.

Biographical notes: Victoria-Eugenia Garcia-Vera is a $\mathrm{PhD}$ Fellow from Alicante University, Spain. She holds a Bachelor in Building Engineering and a Master in Building Management. She gained both degrees from the University of Alicante, where she worked as a part-time lecturer for about five years. She is, also, a member of the EDUTIC-ADEI research group (Alicante University). She is interested into open education resources (OERs) and how the use of information and communication technologies (ICTs) can improve education. Her research is about the use of OERs in the teaching methodology of the building engineering degree. At the end of 2012, she stayed at the Centre for Research Communications of the University of Nottingham, for two months, studying OpenDOAR. 
Rosabel Roig-Vila received her $\mathrm{PhD}$ in Pedagogy from the University of Alicante (Spain), with honors (Summa cum laude and Extraordinary Award). She is a Professor in the University of Alicante. She was the Dean at the Faculty of Education. She specialises in ICT and education, she has published a number of learned papers and monographies, given various lectures on the subject (in Spain and abroad), and received several awards (such as 'Education and Society Award' - 1995 - from the Spanish Government). She is Editor of NAER (http://naerjournal.ua.es/). She has coordinated research projects in Spain and the European Union.

Pedro Garcia Ferrandez received his $\mathrm{PhD}$ in Computing Engineering from the University of Alicante (Spain) and Bachelor in Aeronautical Engineering from the Polytechnic University of Madrid. He is currently a Professor in the Department of Applied Mathematics and a member of the Escuela Politécnica Superior at the University of Alicante. His research interests include applied mathematics mainly focused in numerical computation, teaching and learning methodologies, and the influence of the open access movement in the academic world.

Pablo Marti received his $\mathrm{MSc}$ and $\mathrm{PhD}$ degrees in Architecture from the Technical University of Valencia (Universidad Politécnica de Valencia, UPV), Spain, in 1995 and 2001. He was the academic responsible for the studies of architecture during seven years (2001-2004 and 2007-2011) in the Polytechnic School, University of Alicante. He is currently the Director of the Department of Building Engineering and Urbanism, University of Alicante. He has participated in 13 research networks on innovative education and has participated in several conferences regarding quality in higher education.

\section{Introduction}

The open access (OA) movement is a strategy aiming to disseminate knowledge across society through the internet and had its roots in the scientific world. This movement arose from three declarations: the Budapest Open Access Initiative (2001), the Bethesda Statement on Open Access Publishing (2003), and the Berlin Declaration on Open Access to Knowledge in the Sciences and Humanities (2003). All of them focus on access to scientific literature (including, but not limited to, peer-reviewed journal articles, preprints, preliminary findings, data sets, etc.) that scholars give to the community with limited copyright restrictions, and without expectation of direct monetary return.

Since the MIT (2001) announcement of its OpenCourseWare initiative, followed by the UNESCO Forum in 2002 - when the term Open Educational Resources (OER) was coined - until the World OER Congress of UNESCO in 2012 - when the Paris OER Declaration (2012) was signed -, there have been several Declarations and Guidelines on Open Educational Resources. Underlying all of them is the wish to develop "a universal educational resource available for the whole of humanity" [UNESCO, (2002) p.28]. OER reside in the public domain and are released under an open licence that permits access, use, repurposing, reuse and redistribution by others with no or limited restrictions (Atkins et al., 2007).

OA and OER movements have the common goal of world knowledge sharing and "promoting interaction between them makes sense" [D'Antoni, (2013), p.5]. Both movements have led to the massive proliferation of repositories [i.e., a mechanism for 
storing, managing, maintaining and disseminating digital content for a given community (JISC, 2012; University of Cambridge, 2012)], they are considered part of the digital infrastructure of the modern university (Lynch, 2003; Ware, 2004; Zainab, 2010). It is envisaged that they will host scientific research results and educational resources. Repositories can be indicators of the academic quality of an institution as they concentrate the intellectual production created by the academic community (SPARC, 2002). The emergence of institutional repositories has led to the appearance of repository directories.

This study focuses on intellectual production oriented to education, that is, learning objects (LOs). We consider an LO to be "any digital resource that can be reused to support learning. This definition includes anything that can be delivered across the network on demand, be it large or small" [Wiley, (2000), p.23]. We also define reusability as "the ability to use the same resource multiple times in multiple ways and in multiple contexts" (Robson, 2006). Reusability is considered by Wiley (2000) as the fundamental idea behind LOs, and although some authors do not include explicit references to reusability in their definition, it is considered an implicit requirement by many (Sinclair et al., 2013).

Performing a search is the first phase of the LO reuse process (Clements and Pawlowski, 2012), but where and how can teachers find suitable resources for their use? The answer is straightforward: in repositories. However, it is not so clear which repositories have LOs and how teachers can locate where these repositories are. We believe that directories of open access repositories worldwide (DOARW) are the tools that will help find repositories that contain some LOs - henceforth referred to as LORs, despite the fact that some authors use the acronym LOR to refer to the repositories of learning objects such as MERLOT, JORUM, etc. (Sinclair et al., 2013; Clements and Pawlowski, 2012; McGreal, 2004). Once the LORs are identified, teachers can find needed LOs in the LOR. Nevertheless, DOARW are not very well known, if not completely unknown. In fact, Sinclair et al. (2013, p.180) state that "currently there is no overall directory or way of knowing where, for any given subject of interest, resources reside [...]" although the DOARW dates back to before the publication of that work.

While LO discoverability is a variable that promotes reusability, the existence of critical mass of available content (Clements and Pawlowski, 2012; Davis et al., 2010) also leads to reuse. Indeed, a sufficient amount of open LOs need to exist for there to be a suitable choice, allowing educators to find LOs adapted to specific purposes. Educators may then be able to adapt them, use them and make them available again to other educators.

As teachers in a School of Building Engineering (BE), we are interested in the reuse of LOs relative to our working area, that is, LOs in the field of BE. Hence, we will focus on studying the critical mass of LOs in BE in Spanish repositories in order to use these LOs in the creation of online training. Furthermore, online training in the field of engineering education is particularly interested in providing quality instruction anywhere and at anytime (Almarshoud, 2011; Barbosa et al., 2012; Aichouni et al., 2013; Chen and You, 2010; Salam and Wang, 2009; Yadegaridehkordi et al., 2013).

Therefore, this paper centres on two main objectives:

1 Bringing to light existing DOARW and verifying to what extent they are useful to search Spanish repositories that contain LOs in the field of BE (LOR-BE). This is important firstly because DOARW are unknown to a large part of the academic 
community, and secondly because LOs must be easily found through LORs to ensure high reusability (Robson, 2006; Sinclair et al., 2013; Friesen, 2001).

2 To discover Spanish LORs, especially LORs-BE, and to discover whether critical mass of available content (LOs) has been achieved to promote reuse. Achieving these goals will contribute to developing open knowledge.

\section{Purpose}

The main objectives of this study are specified as follow:

1 to find existing DOARW

2 to determine whether DOARW are useful to find LORs-BE in Spain as a particular case

3 to identify whether there is enough available content in the field of BE to promote reusability.

\section{Methodology}

The repository directories were identified using the Google search engine. The searches were carried out interactively through its website, and the keywords used were 'repository directory', 'directory open access repository', and 'directory lists repositories' among others (the full list can be found in Appendix). In order to find the maximum amount of open access directories, all links were carefully studied as some led to other relevant sources. Directories and search engines that were commercial or limited to one country or knowledge area were excluded.

Studies that in some way used or mentioned repository directories were also taken into account to identify DOARW. The following papers were used:

a Dawson (2013) and Sawant (2013), whose objective was to identify OA resources that can assist researchers and teachers (e.g., repository directories, E-books directories, etc.)

b Abrizah et al. (2010), Lee-Hwa et al. (2013), Melero et al. (2009), Norris et al. (2008), Nyambi and Maynard (2012) and Zainab (2010), who used directories, harvesters, etc. as tools for their own research

c Arachchige and Karunarathna (2012), whose objective was to study the e-resources that scholars from three universities used

d Oliver and Swain (2006), who identified existing directories, and described their scope, record structure and updating mechanism.

The identified DOARW were used to make searches in order to find existing LORs worldwide and in Spain, and then LORs-BE worldwide and in Spain.

To determine whether the results obtained with DOARW, on Spanish LORs-BE, were reliable, the following steps were undertaken: firstly, we obtained a list of all Spanish repositories from each identified DOARW. Secondly, the lists were analysed and 
refined in order to obtain a single list that included all the Spanish repositories. Finally, we visited and analysed every single Spanish repository website on the list, in order to determine the repositories that contained LOs.

The Spanish repositories with LOs were studied to quantify the LO-BEs, and to discover whether critical mass of available content (i.e., enough LOs) in this field was attained to ensure that reuse become a common practice among Spanish teachers.

\section{Results}

\subsection{DOARW identification}

The websites we found that in some way manage repository lists, differ among themselves in purpose or function. We chose to classify them in three different categories:

a directories, named by us DOARW, dedicated to collect, analyse and categorise open access repositories worldwide, and allow advanced searches of open access repositories

b search engines, that allow to search for open access academic/research resources

c websites, that provide some sort of ranking, listings or websites dedicated to a single topic (monographic directories).

\subsubsection{Group A (directories)}

- OpenDOAR (http://www.opendoar.org/), DOAR stands for Directory of Open Access Repositories. Currently, OpenDOAR is funded by the Joint Information Systems Committee (JISC) in collaboration with the Centre for Research Communications (CRC) of the University of Nottingham (UK). OpenDOAR was identified as the leader in repository directories (Oliver and Swain, 2006).

- Registry of Open Access Repository (ROAR) (http://roar.eprints.org/). ROAR is powered by the free software Eprints, both developed by the University of Southampton (UK). ROAR is funded by JISC. OpenDOAR and ROAR are considered the two leading lists of open access repositories worldwide (Suber, 2013).

Both directories in Group A are analysed in the next section.

\subsubsection{Group B (search engines)}

- Bielefeld Academic Search Engine (BASE) (http://www.base-search.net/). BASE is run by Bielefeld University Library (Germany). BASE allows to search contents using keywords. The searches are performed within the content metadata of indexed repositories. BASE does not include the option of 'content type equal to LO' in its search criteria. BASE shows the harvest repository list, but it is not possible to search for repositories that fulfil specific requirements (e.g., country of the repository, repository content, etc.). 
- Digital Repository Infrastructure Vision for European Research (DRIVER) (http://www.driver-community.eu/). DRIVER was co-funded by the European Commission to build a pan-European Infrastructure of freely accessible digital repositories with content spanning across academic disciplines. Only European repositories are integrated. The Driver Project ended in December 2009, although the DRIVER website will be maintained, though not updated, over the medium term. The functioning of BASE and DRIVER is similar: they find the document, supply the document link and the host repository name.

- WorldCat (http://www.worldcat.org/) is a network of library content and services. The WorldCat libraries are dedicated to providing access to their resources on the Web. WorldCat is created and maintained by OCLC (Online Computer Library Center, Inc.). In WorldCat it is possible to search by content type (books, music CDs, videos, digital contents, article citations with links to their full text, etc.) but it is not possible to search by LO.

- Europeana (http://pro.europeana.eu/) has been co-funded by the European Commission. It focuses on European cultural heritage. Europeana aims to promote collaboration between museums, archives, audiovisual collections and libraries so that users can have integrated access to their content. Advanced searches are not allowed in Europeana. It is only possible to specify search results using simple filters (media type, language, date, country, copyright and provider).

\subsubsection{Group C}

\section{C.1: ranking}

- Web Ranking of World Repositories (http://repositories.webometrics.info/): this ranking is an initiative of the Cybermetrics Lab, which belongs to the Consejo Superior de Investigaciones Científicas (CSIC) in Spain. The ranking is published since 2008. The initial ranking list was made with OpenDOAR, ROAR and other sources. Four web indicators (size, visibility, rich files and scholar) are used to establish the ranking, each one assigned with a different weight. For a new repository to be included in the ranking, it must fulfil the following requirements:

1 to have an autonomous web domain or subdomain

2 contents should essentially be scientific papers.

\section{C.2: monographic lists}

- $\quad$ The University of Illinois OAI-PMH Data Provider Registry (http://gita.grainger.uiuc.edu/registry/searchform.asp). This register is maintained by the University of Illinois, and currently has more than 2900 Open Archives Initiative Protocol for Metadata Harvesting (OAI-PMH) repositories. The University of Illinois developed this register to support their own research projects on OAI. The registry was compiled from several sources (Habing et al., 2004): other lists of OAI data providers, Google SOAP APIs (http://www.google.com/apis/index.html), friends container (http://www.openarchives.org/OAI/2.0/guidelines-friends.htm), etc. 
- The Repositories of Primary Sources (http://www.uiweb.uidaho.edu/specialcollections/Other.Repositories.html) was created by the University of Idaho Library. It is a list of over 5000 websites describing physical collections of manuscripts, archives, rare books, historical photographs, oral histories, and other primary sources for researchers.

Groups C.1 and C.2 websites provide several kinds of criteria lists, however searches are not possible.

\section{C.3: lists of repositories using a specific software}

Creators of repository management software often maintain lists of repositories using their software.

- Open Journal Systems (OJS) (http://pkp.sfu.ca/ojs-journals) is a journal management and publishing system developed by the Public Knowledge Project through its efforts to expand and improve access to research. OJS provides a list of over 11,500 journal titles using this system, although the list is not exhaustive.

- DSpace (http://www.dspace.org/whos-using-dspace/Repository-List.html) is an open source software to build digital repositories, set up by MIT. The website's DSpace has a record of all repositories managed with DSpace. It has more than 1,400 repositories registered.

\subsection{Directories used and characteristics}

Our study of repository lists confirms that the two leading lists worldwide are the two in group A (OpenDOAR and ROAR), in accordance with the statement made by Oliver and Swain (2006) and Suber (2013). Therefore, for the purpose of this study, we only used the two websites belonging to group $\mathrm{A}$. The websites in groups $\mathrm{B}$ and $\mathrm{C}$ were excluded because their search engines or listings do not allow refining searches according to specific requirements (e.g., repository country, repository content, etc.) or monographic lists.

OpenDOAR was the first one to be set up, ROAR coming later. Both directories work in a similar way, but there are four important differences:

a ROAR allows end users to add a new repository, following registration and uploading of repository details.

In contrast, OpenDOAR only allows end users to suggest to include a repository;

b before including any repository, OpenDOAR staff confirms that the site has some full resource with unrestricted access, which means for them that the repository embraces the open access philosophy.

However, ROAR does not have any specific criteria for inclusion;

c OpenDOAR details the type of content (e.g., article, books, conferences, LOs, etc.) of all repositories recorded, whereas ROAR classifies each repository in only one type of content 
d OpenDOAR, Celestial and ROARMAP are ROAR sources, and it is possible to restrict the searches in ROAR to any one of them.

However, the searches in ROAR restricted to OpenDOAR do not always match the results directly obtained with OpenDOAR as shown below.

\subsection{Search using DOARW}

Both DOARW provide a full list with the repositories that they contain in their database. Each item of that list shows the main details of the repository (e.g., content type, subject, country, etc.). It is possible to set filters to restrict the search. Each obtained list summarises the total number of registers that are shown. In this section, we present the results obtained using the two identified DOARW.

\subsubsection{LORs found worldwide and in Spain}

To locate all repositories recorded in the DOARW, we performed a search without applying any filter. The result was that 2,257 and 3,361 records were reported by OpenDOAR and ROAR respectively. To search registered LORs, we used the key 'content type' equal to 'learning object' for OpenDOAR and the key 'repository type' equal to 'learning and teaching objects' for ROAR; 348 and 45 records were found respectively. Figure 1 shows the geographical distribution of the registered repositories and within these repositories, those that contain LOs. The internal functioning of ROAR shows that:

a the results of searches by geographical areas do not match the total number of repositories that ROAR registered

b a search in ROAR restricted to OpenDOAR reported 2,349 records.

According to OpenDOAR, there were 12 LORs in Spain, and for ROAR, there were five LORs in Spain.

Figure 1 Number of repositories in OpenDOAR and ROAR per region and number of LOR per region

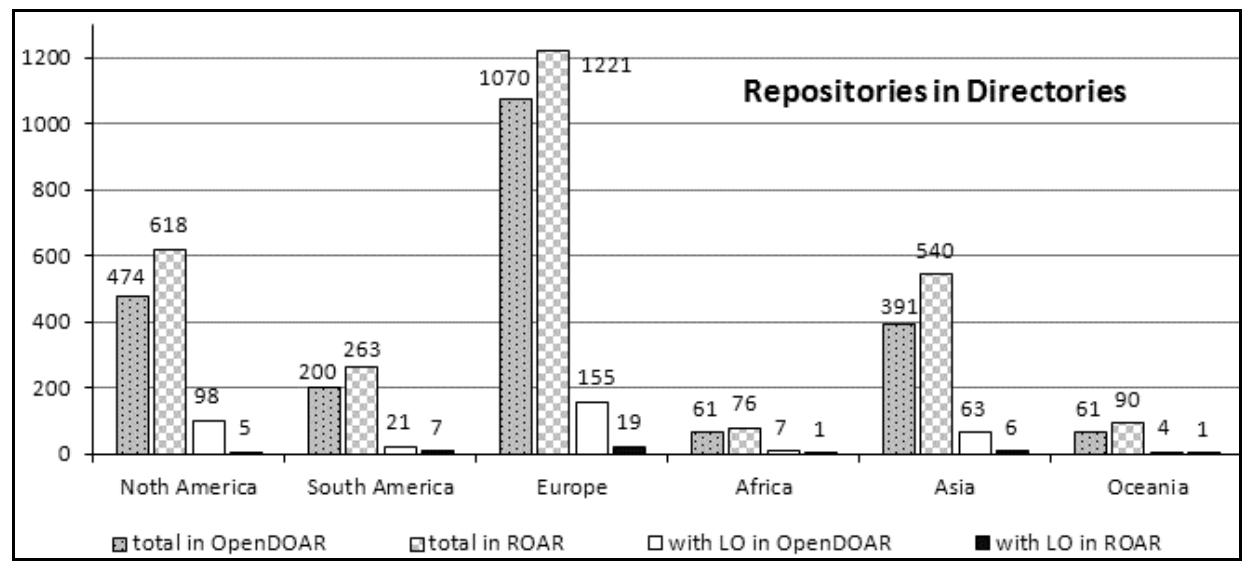


Table 1 Repositories that contain LO in the field of building engineering

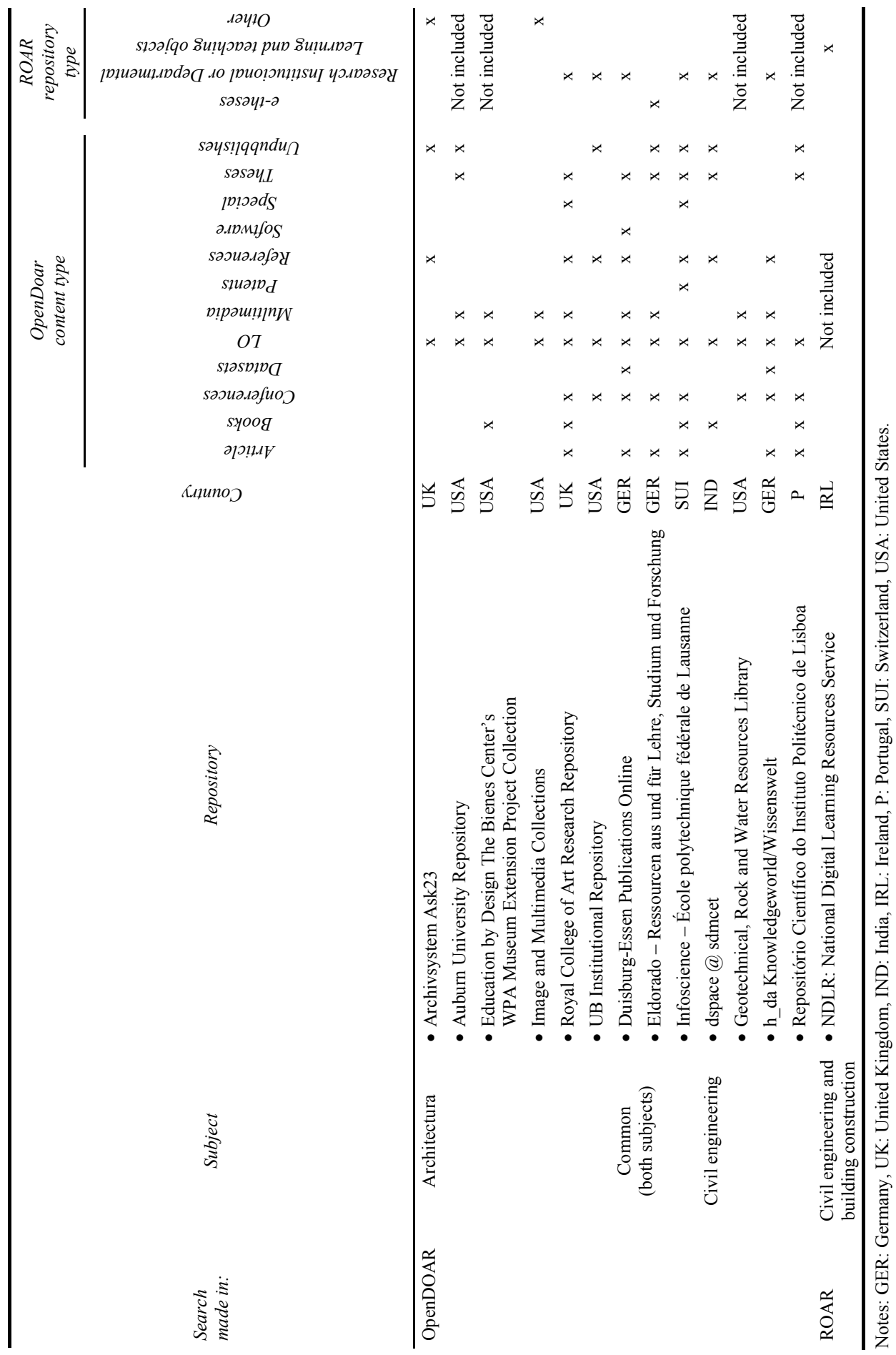




\subsubsection{LOR-BE found worldwide and in Spain}

To find out how many LORs-BE there were worldwide in both DOARWs, searches were filtered by 'subject' and 'content type/repository type'. The searches were filtered through a list box that differed from one directory to another. So to carry out this study, the most similar subjects related to BE were chosen. For OpenDOAR the subjects chosen were 'architecture' and 'civil engineering', and for ROAR, 'civil engineering' and 'building construction' were selected. The search results are shown in Table 1, and can be summarised as follow:

a in OpenDOAR, six for 'architecture', four for 'civil engineering' and three for both subjects

b in ROAR, one common repository for both subjects.

None of the repositories listed in Table 1 was Spanish.

The differences shown in Subsection 4.3.1 and 4.3.2 (on the number of LORs and LORs-BE obtained searching in both directories) did not seem reasonable, since OpenDOAR is a source of ROAR, and consequently, a search made in ROAR should at least show the repositories registered in OpenDOAR. Therefore, we examined the LORs-BE listed in both directories in detail (the main details of the repositories listed are also included in Table 1). Predictably, nine repositories appearing in OpenDOAR were in ROAR's database, however they did not appear as a result of the search of LORs-BE made with ROAR. A possible explanation for this discrepancy is the way repositories are labelled at the metadata level. In ROAR, repositories that include various contents (articles, books, theses, LOs, etc.) are labelled as only one type of content. By contrast, OpenDOAR labels the repositories enumerating each one of the elements that they contain.

However, based on previous experience, the authors knew that Spanish repositories containing LO-BEs did exist. Despite this fact, no Spanish LOR-BE was produced by the search results. That could indicate a possible malfunctioning in DOARW. Consequently, we studied all Spanish repositories one by one.

\subsection{Inspecting the Spanish repositories}

To inspect all Spanish repository websites, we made up a list obtained from OpenDOAR and ROAR. To do this, we performed a search in each directory using the country field (with value 'Spain') as the only filter criterion. We obtained two raw lists, one for each directory, with 97 items for OpenDOAR and 131 for ROAR.

Based on the analysis of the raw lists, we found that:

a all records listed in OpenDOAR corresponded to real repositories that follow open access philosophy

b in the ROAR list, the following anomalies were found: one repository was listed three times, 22 repositories were listed twice, five records contained only metadata, three records were journals, two websites had no relation with the academic world, and two repositories had access control and therefore were not open access.

After removing repeated records and those that were not really repositories, 95 real repositories were obtained from ROAR. 
Comparing the two lists of real repositories, we saw there were common repositories, and other repositories that existed only in OpenDOAR or only in ROAR; a final list of 100 repositories was obtained from the merger of both lists (the final list is available from the authors).

Finally, we visited and analysed the repositories in the list one by one. We found that most of the Spanish repositories used DSpace Software, and Dublin Core (http://dublincore.org/) and OAI-PMH (http://openarchives.org/) protocols for metadata codification. Nevertheless, the visited repositories had a different hierarchical structure, with distinct labels for each hierarchical level. Moreover, metadata sets that describe stored resources were not common to all repositories.

We deduced that the repository had teaching materials when the Spanish words in Appendix were present (e.g., teaching materials, educational digital resources, etc.). Following the analysis of each repository, we found that 35 repositories contained teaching materials, in contrast to the 12 repositories of OpenDOAR and five of ROAR. However, it was also found that, in many repositories, the teaching materials section did not contain LOs, but had final bachelor's degree projects, master's degree projects, monographs or student work.

In Table 2, we list the 35 repositories that contain LOs. To locate the LOR-BE within the 35 repositories we used the Spanish keywords listed in Appendix. We considered that these keywords could describe the specific training modules of the Building Engineering degree. Possible words describing basic training modules were rejected.

We found that 13 out of 35 repositories contained LOs in BE, which contradicts the results obtained through the directories. In the OpenDOAR case, the discrepancy is due to some repositories containing different subjects that are classified as 'multidisciplinary'. Hence, they do not appear as a result of searches by a particular subject. In the ROAR case, information needed for cataloguing the subjects of the repositories is not provided.

The repositories that contain the most LOs in BE are (Table 2):

- ACCESS, from the University of Las Palmas de Gran Canaria, which has 18 pdf files on the subject of architecture

- DUGiMedia, from the University of Girona, with 50 audio files (mp3) in physics applied to building engineering, without any additional instructional support

- $\quad R U A$, from the University of Alicante, with 33 LOs in different formats (pdf, ppt, video, and html)

- RiuNet, from the Polytechnic University of Valencia, with four virtual laboratories and 119 educational videos

- UPCommons, from the Polytechnic University of Catalonia, with four OpenCourseWare (OCW), 49 instructional videos, and numerous photos. 
Table 2 Study of Spanish repositories

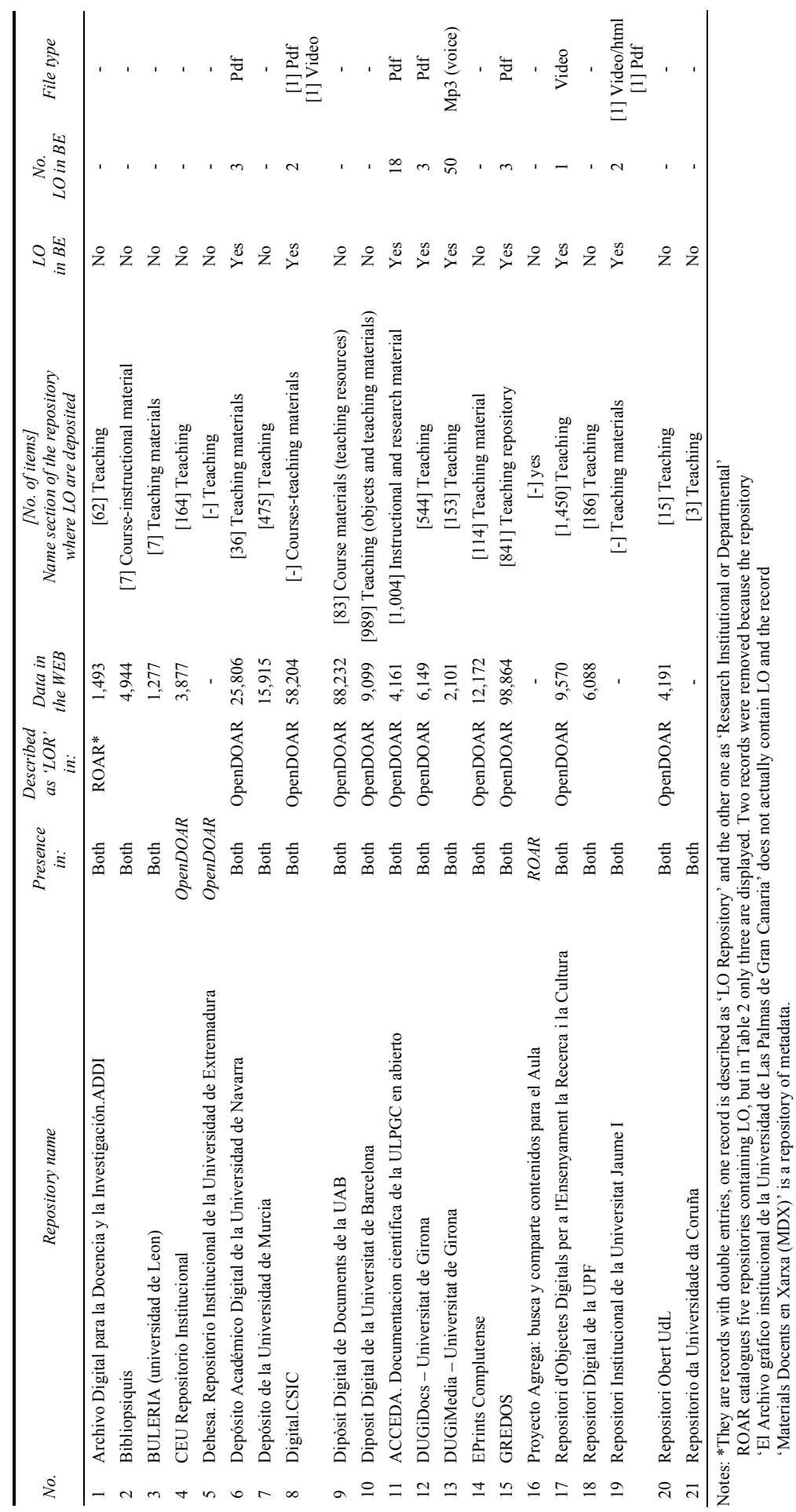


Table 2 Study of Spanish repositories (continued)

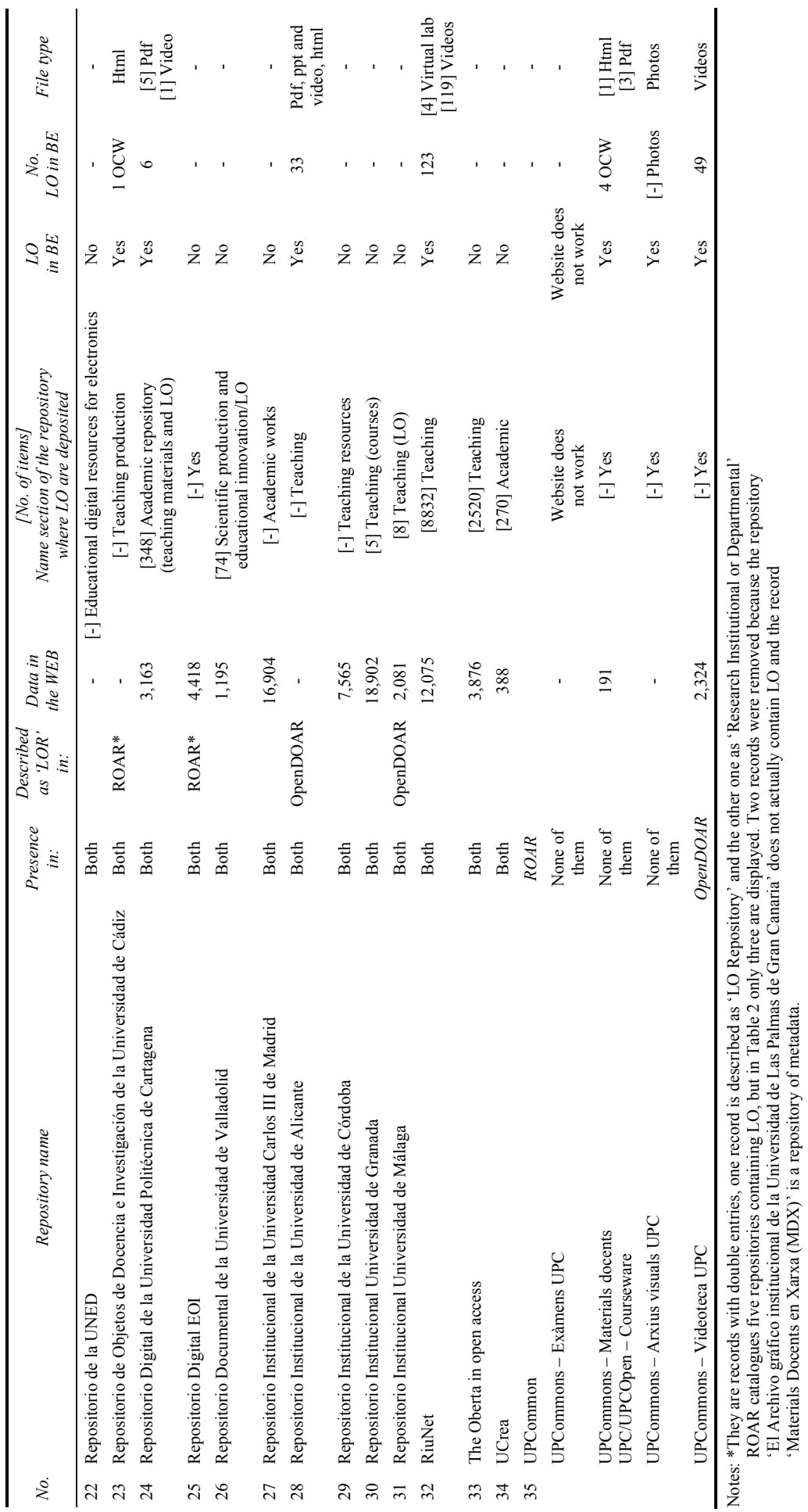




\section{Discussion}

The search results to find DOARW show that several websites exist that in some way manage repository lists. These websites have different purposes or functions and fall into three different categories: directories, search engines, and websites that provide some sort of ranking, listings or websites dedicated to a single topic (monographic directories). Only two directories were found, OpenDOAR and ROAR.

Search results for LORs-BE worldwide using both DOARW do not match (13 LORs in OpenDOAR and one in ROAR; none of them Spanish). This discrepancy is due to the way repositories are labelled. In ROAR, repositories that include various contents are labelled with only one type of content, so search results using ROAR are less accurate than when using OpenDOAR. This finding shows it would be necessary to label repository content very precisely to make searches accurate.

Search results for Spanish repositories using both DOARW do not match either: 97 repositories in OpenDOAR and 131 in ROAR. That is because ROAR does not have any criteria of inclusion. As a result, ROAR contains repeated records, records that are metadata-only repositories, records that are not repositories, and records that are repositories with access control. However, OpenDOAR staff analyses each new repository and decides whether to include it or not in its database according to their own criteria. This result shows that OpenDOAR is more rigorous than ROAR. In the case of ROAR, it would be advisable that ROAR revise repositories before including them into its database.

The detailed study of Spanish repositories shows that the existing Spanish LORs (35) do not match those obtained through DOARW. In the OpenDOAR case (12 LORs), the difference is due to an error in the inclusion process of the repository into its database. In the ROAR case (five LORs), it is because ROAR only allows one type of content in the codification of the registered repositories.

Likewise, the Spanish LORs-BE (13) obtained in the study do not match those found using DOARW (0). In the OpenDOAR case, the discrepancy is due to some repositories containing different subjects that are classified as 'multidisciplinary'. Hence, they do not appear as a result of searches by a particular subject. In the ROAR case, the information needed for cataloguing repository subjects of the repositories is not provided. This result indicates that DOARW do not currently produce accurate results in searches for Spanish LORs-BE.

It has been proved that Spanish LORs-BE exist but they are not listed in directories. It is a fact that there are mistakes in the way repositories are labelled in directories. Therefore, it could be inferred that the DOARW's data on LORs worldwide (348 in the case of OpenDOAR, and 45 in the case of ROAR) is unreliable. It is important that minor deficiencies of DOARW be remedied. Otherwise, searches using the data obtained from the directories as information sources (Abrizah et al., 2010; Lee-Hwa et al., 2013; Melero et al., 2009; Norris et al., 2008; Nyambi and Maynard, 2012; Zainab, 2010) may be inaccurate.

Today, the contribution from Spanish universities to the knowledge society via LO is scarce. If we focus our attention on the field of BE, Spain's contribution is even poorer being mainly limited to pdf files (e.g., manuals, problem collections, etc.) and video recordings of master lectures. The most active universities in the creation of 'sophisticated' LOs in BE are the University of Alicante and the Polytechnic University of Valencia. 


\section{Conclusions}

This study has achieved the three specific objectives set out:

\subsection{Existing DOARW}

This work brings to light the existence of DOARW (OpenDOAR y ROAR) tools which are not well known by the academic and research communities. This study contributes to promote awareness of these powerful tools for collecting and making open access repositories worldwide available to scholars and researchers from a single website. They definitely represent great progress and stem from the open access movement towards accessibility of scientific/academic production.

However, in our opinion, the most useful directory is OpenDOAR for the following two reasons:

1 ROAR assigns each repository only one content type tag

2 OpenDOAR staff analyses each new repository prior to its inclusion in its database.

In the search process of DOARW, we discovered search engines (BASE, DRIVER, OAIster and Europeana). These engines look through institutional repositories but they do not allow to search by LO. This option would be desirable as these search engines already offer sophisticated and advanced search options.

\subsection{Usefulness of DOARW to find Spanish LORs-BE}

Currently DOARW are not very useful to find Spanish LORs-BE. This work shows that DOARW needs to improve the way repositories are labelled in order to be effective as repository location tools. This will allow search results, using DOARW, to include all repositories fulfilling the search criteria specified. However, as this study shows, this is not currently happening, so research based on DOARW's data may be inaccurate.

As a result of the detailed study on Spanish repositories listed in DOARW, we have located all Spanish LORs and LORs-BE. The results obtained may be useful for the Spanish academic community interested in reusing LOs, saving them from having to repeat this extensive study.

This study also confirms that there is no unified criteria on how to label the section where LOs are stored in Spanish repositories. Furthermore, there is no common criteria for the metadata set that describes teaching materials. These malfunctions make it difficult to locate LOs in Spanish repositories. It would be advisable that national education authorities promote the establishment of common criteria for repository structuring and metadata of teaching materials.

Future research could focus on how teaching materials are organised in repositories worldwide, and propose a common model, so as to unify the way teaching materials are stored, in the same way as research materials.

\subsection{Existing LOs in the field of BE in Spain}

This study shows that there are LOs in BE in Spain, but there are not enough. Critical mass of LOs in $\mathrm{BE}$ is not attained, and this represents a barrier to reusability. We believe 
the movement towards open knowledge will be set back if no measure is taken to enhance the spirit of sharing academic production in the field of BE in Spain.

\section{Acknowledgements}

This work has been carried out with the support of the Vicerrectorado de Investigación, Desarrollo e Innovación of the University of Alicante, addressing the training of $\mathrm{PhD}$ students, Ref. UAFPU 2011-33487413B.

\section{References}

Abrizah, A., Noorhidawati, A. and Kiran, K. (2010) 'Global visibility of Asian universities' open access institutional repositories', Malaysian Journal of Library \& Information Science, Vol. 15, No. 3, pp.53-73.

Aichouni, M., Benchicou, S. and Nehari, D. (2013) 'Knowledge management through the e-learning approach - a case study of online engineering courses', European Journal of Engineering Education, Vol. 38, No. 3, pp.316-328.

Almarshoud, A.F. (2011) 'The advancement in using remote laboratories in electrical engineering education: a review', European Journal of Engineering Education, Vol. 36, No. 5, pp.425-433.

Arachchige, J.J.G. and Karunarathna, A. (2012) 'Commercial vs. open access: use among academics of engineering faculties of Sri Lanka', National Library Journal, Vol. 1, No. 1, pp.11-16.

Atkins, D.E., Brown, J.S. and Hammond, A.L. (2007) A Review of the Open Educational Resources (OER) Movement: Achievements, Challenges, and New Opportunities, Report to The William and Flora Hewlett Foundation [online] http://www.hewlett.org/uploads/files/Hewlett_OER_report.pdf (accessed January 2014).

Barbosa, J.L.V., Hahn, R., Barbosa, D.N.F. and Segatto, W. (2012) 'Intensive use of mobile technologies in a computer engineering course', Computer Applications Engineering Education, doi: 10.1002/cae.21560.

Berlin Declaration on Open Access to Knowledge in the Sciences and Humanities (2003) [online] http://oa.mpg.de/berlin-prozess/berliner-erklarung/ (accessed April 2013).

Bethesda Statement on Open Access Publishing (2003) [online] $\mathrm{http}: / /$ legacy.earlham.edu/ peters/fos/bethesda.htm (accessed January 2014).

Budapest Open Access Initiative (2001) [online] http://www.opensocietyfoundations.org/openaccess/read (accessed April 2013).

Chen, W. and You, M. (2010) 'Student response to an internet-mediated industrial design studio course', International Journal of Technology and Design Education, Vol. 20, No. 2, pp.151-174.

Clements, K.I. and Pawlowski, J.M. (2012) 'User-oriented quality for OER: understanding teachers' views on re-use, quality, and trust', J. Computer Assisted Learning, Vol. 28, No. 1, pp.4-14, doi:10.1111/j.1365-2729.2011.00450.x.

D'Antoni, S. (2013) A World Map of Open Educational Resources Initiatives: Can the Global OER Community Design and Build it Together?, Summary Report of an International Conversation, 12-30 November 2012, Athabasca University.

Davis, H.C., Carr, L., Hey, J.N., Howard, Y., Millard, D., Morris, D. and White, S. (2010) 'Bootstrapping a culture of sharing to facilitate OER', IEEE Transactions on Learning Technologies, Vol. 3, No. 2, pp.96-109. 
Dawson, D. (2013) 'Making your publications open access: resources to assist researchers and librarians', College \& Research Libraries News, Vol. 74, No. 9, pp.473-476 [online] http://crln.acrl.org/content/74/9/473.full (accessed January 2014).

Friesen, N. (2001) 'What are educational objects?', Interactive Learning Environments, Vol. 9, No. 3, pp.219-230.

Habing, T.G., Cole, T.W. and Mischo, W.H. (2004) 'Developing a technical registry of OAI data providers', in Heery, R. and Lyon, L. (Eds.): Research and Advanced Technology for Digital Libraries, Lecture Notes in Computer Science (Series Vol. 3232), pp.400-410, Springer, Berlin, Heidelberg.

Joint Information Systems Committee (JISC) (2012) Digital Repositories InfoKit [online] //tools.jiscinfonet.ac.uk/downloads/repositories/digital-repositories.pdf (accessed May 2014).

Lee-Hwa, T., Abrizah, A. and Noorhidawati, A. (2013) 'Availability and visibility of open access digital repositories in ASEAN countries', Information Development, Vol. 29, No. 3, pp.274-285, DOI: 10.1177/0266666912466754.

Lynch, C.A. (2003) Institutional Repositories: Essential Infrastructure for Scholarship in the Digital Age, Report No. 226, pp.1-7, ARL BiMonthly.

McGreal, R. (2004) 'Learning objects: a practical definition', International Journal of Instructional Technology and Distance Learning, Vol. 1, No. 9, pp.21-32.

Melero, R., Abadal, E., Abad, F. and Rodríguez-Gairín, J.M. (2009) 'The situation of open access institutional repositories in Spain: 2009 report', Information Research, Vol. 14, No. 4 [online] http://informationr.net/ir/14-4/paper415.html (accessed July 2013).

MIT (2001) MIT Launches Online Learning Initiative [online] web.mit.edu/newsoffice/2011/mitxeducation-initiative-1219.html (accessed July 2013).

Norris, M., Oppenheim, C. and Rowland, F. (2008) 'Finding open access articles using Google, Google Scholar, OAIster and OpenDOAR', Online Information Review, Vol. 32, No. 6, pp.709-715.

Nyambi, E. and Maynard, S. (2012) 'An investigation of institutional repositories in state universities in Zimbabwe', Information Development, Vol. 28, No. 1, pp.55-67.

Oliver, K.B. and Swain, R. (2006) 'Directories of institutional repositories: research results \& recommendations', Paper presented at the World Library and Information Congress: 72nd IFLA General Conference and Council, 20-24 August 2006, Seoul, Korea [online] http://archive.ifla.org/IV/ifla72/papers/151-Oliver_Swain-en.pdf (accessed April 2013).

Paris OER Declaration (2012) http://www.unesco.org/new/fileadmin/MULTIMEDIA/HQ/CI/CI/pdf/Events/Paris\%20OER\% 20Declaration_01.pdf (accessed April 2013).

Robson, R. (2006) 'Reusability and reusable design', in Dempsey, J.V. and Reiser, R.A. (Eds.): Trends and Issues in Instructional Design, 2nd ed., pp.301-309, Merill/Prentice-Hall, Upper Saddle River, New Jersey.

Salam, S. and Wang, Q. (2009) 'Designing a web-based learning environment using weblogs and podcasts', International Journal of Continuing Engineering Education and Life-Long Learning, Vol. 19, Nos. 2-3, pp.179-190.

Sawant, S. (2013) 'Open access resources useful in LIS education', Library Hi Tech News, Vol. 30, No. 7, pp.16-20.

Scholarly Publishing and Academic Resources Coalition (SPARC) (2002) Institutional Repository Checklist \& Resource Guide [online] http://www.arl.org/sparc/bm doc/IR_Guide_\&_Checklist_v1.pdf (accessed April 2013).

Sinclair, J., Joy, M., Yin-Kim, J. and Hagan, S. (2013) 'A practice-oriented review of learning objects', IEEE Transactions on Learning Technologies, Vol. 6, No. 2, pp.177-192.

Suber, P. (2013) Open Access Overview. Focusing on Open Access to Peer-Reviewed Research Articles and Their Preprints [online] http://www.earlham.edu/ peters/fos/overview.htm (accessed April 2013). 
UNESCO (2002) Forum on the Impact of Open Courseware for

Higher Education in Developing Countries-Final Report, UNESCO [online]

http://portal.unesco.org/ci/en/files/2492/10330567404OCW_forum_report_final_draft.doc/OC W_forum_report_final_draft.doc (accessed July 2013).

University of Cambridge (2012) Digital Repositories [online] http://www.lib.cam.ac.uk/dataman/pages/repositories.html (accessed May 2014).

Ware, M. (2004) Universities' Own Electronic Repositories Yet to Impact on Open Access, Nature Publishing Group [online] http://www.nature.com/nature/focus/accessdebate/4.html\#b4 (accessed May 2013).

Wiley, D.A. (2000) Learning Object Design and Sequencing Theory, Unpublished PhD Thesis, Department of Instructional Psychology and Technology. Brigham Young University, Provo, Utah, USA.

Yadegaridehkordi, E., Iahad, N.A. and Baloch, H.Z. (2013) 'Success factors influencing the adoption of M-learning', International Journal of Continuing Engineering Education and Life-Long Learning, Vol. 23, No. 2, pp.167-178.

Zainab, A.N. (2010) 'Open access repositories and journals for visibility: implications for Malaysian libraries', Malaysian Journal of Library \& Information Science, Vol. 15, No. 3, pp.97-119. 


\title{
Appendix
}

\author{
Google search keywords
}

"repository directory"; "repository list"; "repository registry"; "directory open access repository"; "registry open access repository"; "list open access repository"; "directory lists repositories"; "registry lists repositories".

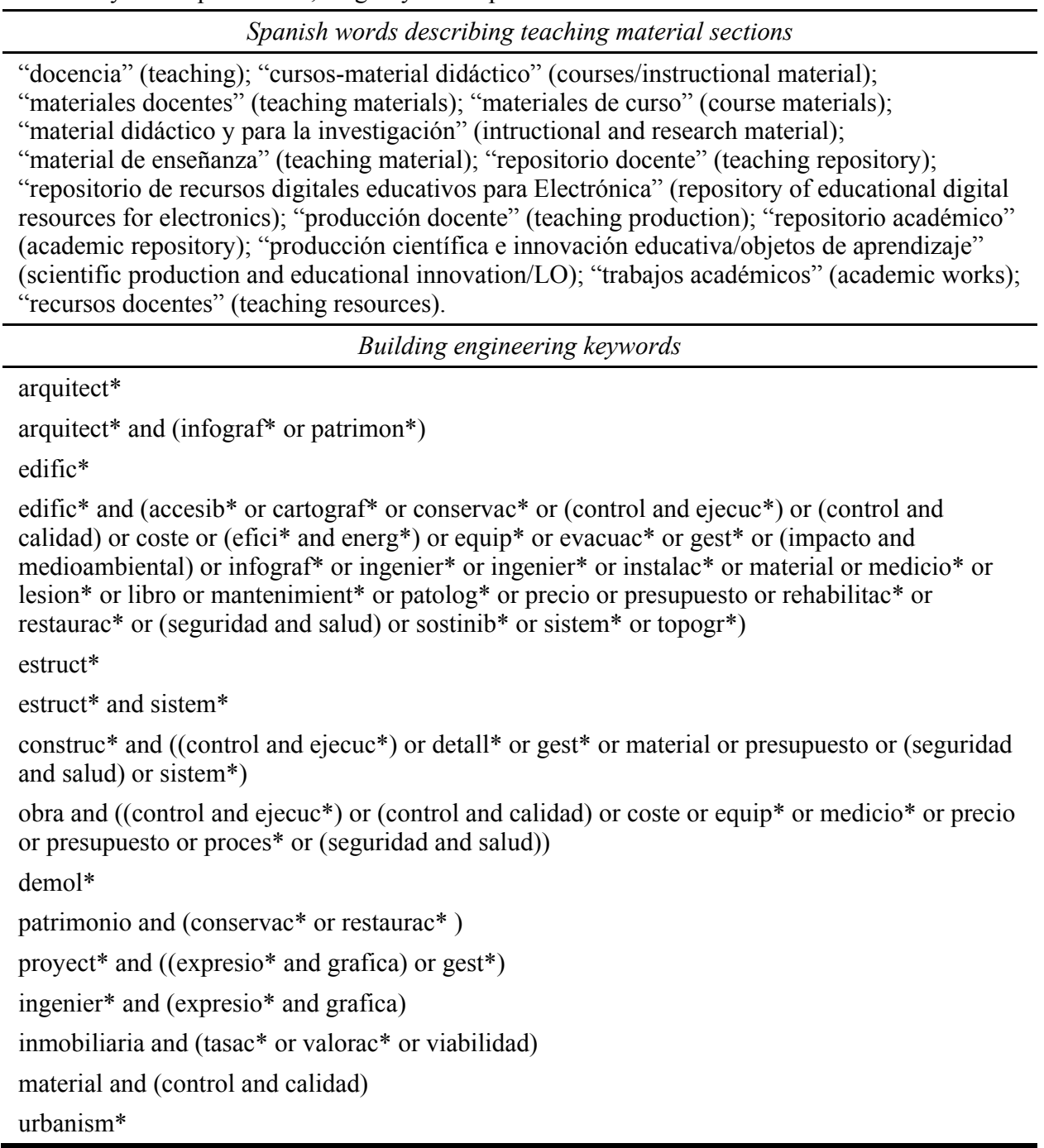

